\section{Quantification of Streptococcus mutans in Different Types of Ligature Wires and Elastomeric Chains}

Mariana Umekita Shirozaki ${ }^{1}$, José Tarcísio Lima Ferreira ${ }^{1}$, Erika Calvano Küchler ${ }^{1}$, Mírian Aiko Nakane Matsumoto ${ }^{1}$, Carolina Patrícia Aires ${ }^{2}$, Paulo Nelson-Filho ${ }^{1}$, Fábio Lourenço Romano ${ }^{1}$

\author{
'Department of Pediatric Dentistry, \\ School of Dentistry of Ribeirão \\ Preto, USP - Universidade de São \\ Paulo Ribeirão Preto, SP, Brazil \\ ${ }^{2}$ Department of Physics and \\ Chemistry, School of Pharmaceutical \\ Sciences of Ribeirão Preto, \\ USP - University of São Paulo, \\ Ribeirão Preto, SP, Brazil
}

Correspondence: Fábio Lourenço Romano, Avenida do Café s/n, Monte Alegre, 14090-904. Ribeirão Preto, SP, Brasil. Tel: 55-16-3315-4146. e-mail: fabioromano@forp.usp.br

Key Words: Streptococcus mutans, biofilm, orthodontic.

\section{Introduction}

Orthodontic appliances are made from a variety of solid and elastic materials with irregular surfaces and these irregularities increase the retention of food residue, making mechanical hygiene difficult $(1,2)$, increasing microbial contamination (3-6). Orthodontic appliances can change oral microflora, increase the levels of periodontal pathogens (7) and Streptococcus mutans $(1,8-10)$ in the saliva and dental biofilms during orthodontic treatment.

Although many microorganisms are involved in caries pathogenesis, S. mutans is the most directly involved in caries etiology (11). In accumulated biofilms, decreased $\mathrm{pH}$ results from the fermentation of dietary carbohydrates from cariogenic bacteria, such as $S$. mutans, which survive and predominate in an acidic environment (12).

Fixed orthodontic mechanotherapy is an aggravating factor because it uses materials that increase the levels of cariogenic microorganisms within the dental biofilm and on the surface of orthodontic appliances $(9,2,13,14)$. Such changes may be responsible for the increased susceptibility to the development of carious lesions, with or without cavitation, during orthodontic treatments $(10,15)$.

Metal ligatures, like steel ties and elastomeric ligatures, like elastic chains, are among the most widely used orthodontic devices. Steel ties (non-hardened stainlesssteel wires) of different diameters $(0.08 ", 0.10 ", 0.12 ")$, which join two or more teeth, are used for anchorage, to support moving teeth, for rotation correction, to prevent the opening of diastemas, to support intermaxillary elastics and as guide wires for dental traction. When used for anchorage, these ties work by joining two or more teeth by crossing either over or under an archwire inserted in the bracket slot or placed in a figure-eight configuration. In addition to these devices, elastics are present in many orthodontic treatments as elastomeric ligatures, intra- and extra-oral elastics, elastic chains and other devices that are critically important for corrective mechanics. It was previously shown that elastomeric ligatures may become intensely contaminated with S. mutans (16); however, no published studies assessed which ligature types exhibit higher cariogenic microorganism accumulation on their surfaces. Such investigations allow selection of the most appropriate ligature types for clinical use according to microbiological parameters. Thus, the aim of this clinical study was to test the hypothesis that $S$. mutans contamination levels differ according to the type of the ligature.

\section{Material and Methods}

This study was approved by the Research Ethics Committee (\# 0031.0.138.212-11). This study was explained in detail to the patients and/or their legal guardians.

\section{Sample Selection}

Sample size estimation was calculated according to a previous study (17), which evaluated the alterations on 
microbial flora after orthodontic bonding of two different archwire ligation techniques (elastomeric rings and ligature wires). The sample size calculation was performed according to the mean value of $S$. mutans and the standard deviation presented in the different archwire ligation techniques in the first week. A calculator (https://www.stat.ubc.ca) was used to determine the minimum sample size required for paired sample, a $\alpha$ of $5 \%$ and a power of $80 \%$ in which the mean S. mutans was 5.26 in the elastomer group, 4.79 in the ligature group and a common standard deviation of 0.40 . The estimated sample size for the study was 12 per type of ligature, therefore it was decided to include a sample of 13 patients due to the possibility of drop-out.

A sample of patients undergoing fixed orthodontic treatment in the Orthodontics Residence at the University was selected for this study. Healthy non-smoking patients of both genders with complete permanent dentition and no carious lesions or periodontal disease were selected. Patients who had used antibiotics or antimicrobial mouthwashes within the previous 3 months were excluded. In addition, dental biofilm samples from the cervical third of the buccal surface of the first maxillary premolars, adjacent to the bracket, were collected to confirm the presence of S. mutans. The collection was performed using a plastic curette (Jon, São Paulo, SP, Brazil) and S. mutans quantification was checked using Mitis Salivarius Bacitracin (MSB) agar, which is selective for S. mutans $(18,19)$.

Thirteen patients ( 5 males and 8 females) aged between 11 and 22 years (mean age of 13.8 years), who met the inclusion criteria, were selected. Patients were handed an "oral hygiene kit" containing a toothbrush (Professional; Colgate-Palmolive Indústria e Comércio Ltda, São Paulo, $\mathrm{SP}$, Brazil) and fluoride toothpaste (Colgate Maximum Cavity Protection, Colgate-Palmolive). The patients were instructed to maintain an oral hygiene routine by brushing their teeth three times per day after meals.

\section{Experimental Design}

In this in vivo cross-sectional study, four treatments were assessed in each of the 13 patients. All the devices were made and fitted by the same operator (MUS) and each quadrant was subjected to one of the following randomly determined ligature-use protocols (Fig. 1): Group I: elastomeric ligature (elastic chain) $(n=13) ;$ Group II: steel ligature crossing over the archwire $(n=13)$; Group III: steel ligature crossing under the archwire $(n=13)$; Group IV: steel ligature crossing in a figure-eight pattern under the archwire $(n=13)$.

\section{Treatments}

Untempered 0.10" stainless steel ligature wire was used to make the metal ligatures for Groups II, III and IV (Morelli, Sorocaba, SP, Brazil). Coon tying pliers (Ortoply, Philadelphia, PA, USA) were used to stretch the ligature wire, connecting the teeth. For Group I, conventional elastomeric ligatures (elastic chains) were used (Morelli). All ligatures were fitted while the patients were wearing maxillary and mandibular 0.020" alignment and leveling stainless-steel archwires, brackets standard Edgewise slot 022" (Morelli). When the metal ligatures were fitted under
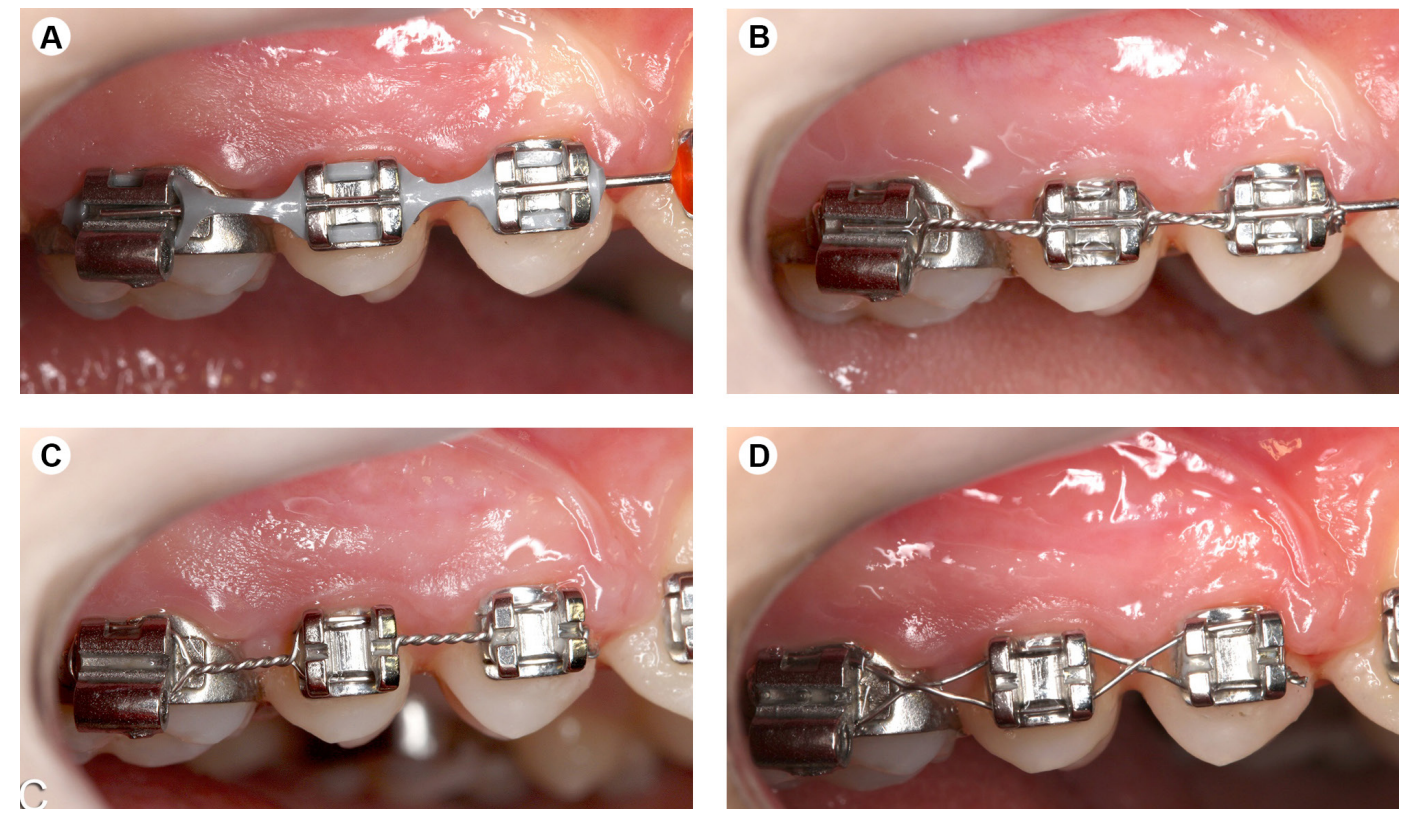

Figure 1. Clinical photographs of the devices: A: elastomeric chain ligature; B: Steel ligature tie crossing over the archwire; C: Steel ligature tie crossing under the archwire and D: Steel ligature tie crossing in a figure-eight pattern under the archwire. 
the wire (Groups III and IV), the 0.020" arch was fixed to a bracket with individual elastomeric ligatures (Morelli).

After seven days, the patients were reviewed in the morning in fasting and not brushed their teeth. Each of the ligatures was removed and cut in half using ligature cutters (Ortoply, Philadelphia, PA, USA) by the same operator (MUS). The cut was made between the bracket wing of the second pre-molar to divide the ligatures in half. The anterior portion of the ligature was used for microbiological analysis, and the posterior portion was used for scanning electron microscopy (SEM) analysis.

\section{Microbiological Analysis}

After the assigned experimental time, the ligatures containing the biofilms were individually transferred to preweighed microcentrifuge tubes $( \pm 0.01 \mathrm{mg}$; Analytical Plus AP 250D, Ohaus Corp, Florham Park, NJ, USA) containing $1 \mathrm{~mL}$ of $0.9 \% \mathrm{NaCl}$. The tubes were sonicated to detach the biofilms formed on the ligatures and to improve homogenization (20). The ligatures were carefully removed from the suspension and weighed. The weight of biofilm was calculated by the difference in the weight of tube and ligature. Aliquots of the biofilm suspension were diluted $\approx$ in series $(1: 1,1: 10,1: 100$, and $1: 1000)$ with $0.9 \% \mathrm{NaCl}$ and were plated onto Mitis Salivarius agar plus 0.2 units of bacitracin/mL and 15\% of sucrose (MSB), for mutans streptococci group (18) using the drop-plate technique. The plates were incubated for $48 \mathrm{~h}$ at $37^{\circ} \mathrm{C}$ in anaerobic conditions with 5\% $\mathrm{CO}_{2}$ (MCO-19AICUV, Sanyo Electric Co., Ltd. Osaka, Japan). The colony-forming units (CFU) were counted and the results expressed in $\log _{10} \mathrm{CFU} / \mathrm{mg}$ dental biofilm wet weight.

\section{Scanning Electron Microscopy (SEM)}

After the devices were cut, the posterior portions of each ligature from 3 patients, totalizing 12 ligatures (3 elastomeric ligature; 3 steel ligature crossing over the archwire; 3 steel ligature crossing under the archwire; and 3 steel ligature crossing in a figure-eight pattern under the archwire) were immediately placed in jars containing a 3\% glutaraldehyde solution. After $48 \mathrm{~h}$, the specimens were rinsed with distilled water and sequentially immersed in increasing concentrations of alcohol $(30,50,70,80$, and $90 \%$, followed by three sequential immersions in 100\% alcohol) for $10 \mathrm{~min}$ at each concentration. For electron microscope analysis, the specimens were critical-point dried in an EMS 850 device using $\mathrm{CO}_{2}$ and mounted on metal stubs with adhesive tape and conductive silver glue. Next, the specimens were gold-sputtered for $60 \mathrm{~s}$ using a Denton Vacuum Desk II device. The samples were analyzed using a scanning electron microscope (JSM 5410, Jeol, Tokyo, Japan) at a voltage of $15 \mathrm{kV}$. Electron micrographs (15-5000 x magnification) were taken to demonstrate in vivo the presence or absence of biofilm formation via SEM.

\section{Statistical Analysis}

The data were analyzed with the SAS System (SAS Institute Inc. The SAS System, release 9.2. SAS Institute Inc., Cary, NC, USA, 2008). Response variables did not fulfill the assumptions of equality of variances and normal distribution of errors. Thus, a generalized linear mixed model was adjusted for log-normal distribution for an experiment with a random effect (volunteers) for fixed-effect test (wire). After transformation, the adherence of the residuals

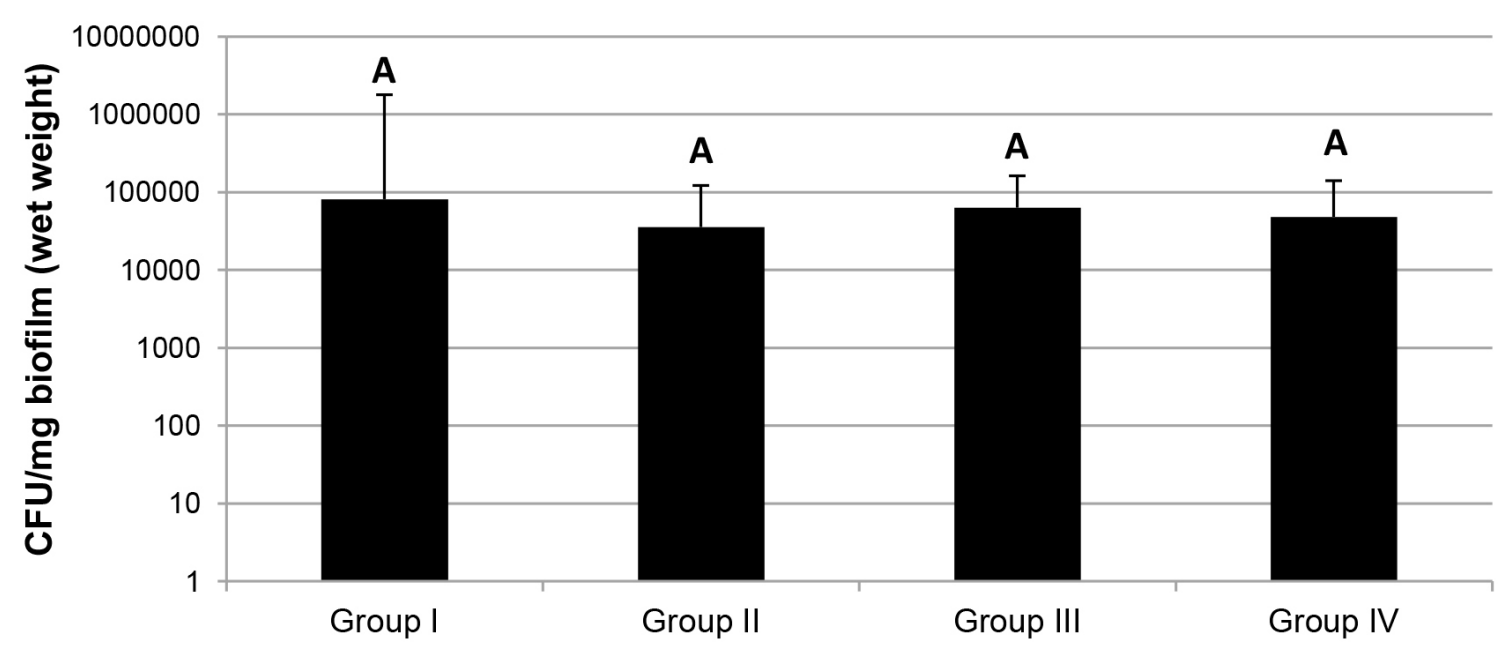

Figure 2: Streptococcus mutans viability according the experimental groups $(\mathrm{n}=13)$. Data were submitted to Analysis of Variance (ANOVA) and compared by Tukey-Kramer test. Same letters indicate that there was no statistical significant difference among groups (p>0.05). Group I: elastomeric ligature (elastic chain); Group II: steel ligature crossing over the archwire; Group III: steel ligature crossing under the archwire; Group IV: steel ligature crossing in a figure-eight pattern under the archwire. 

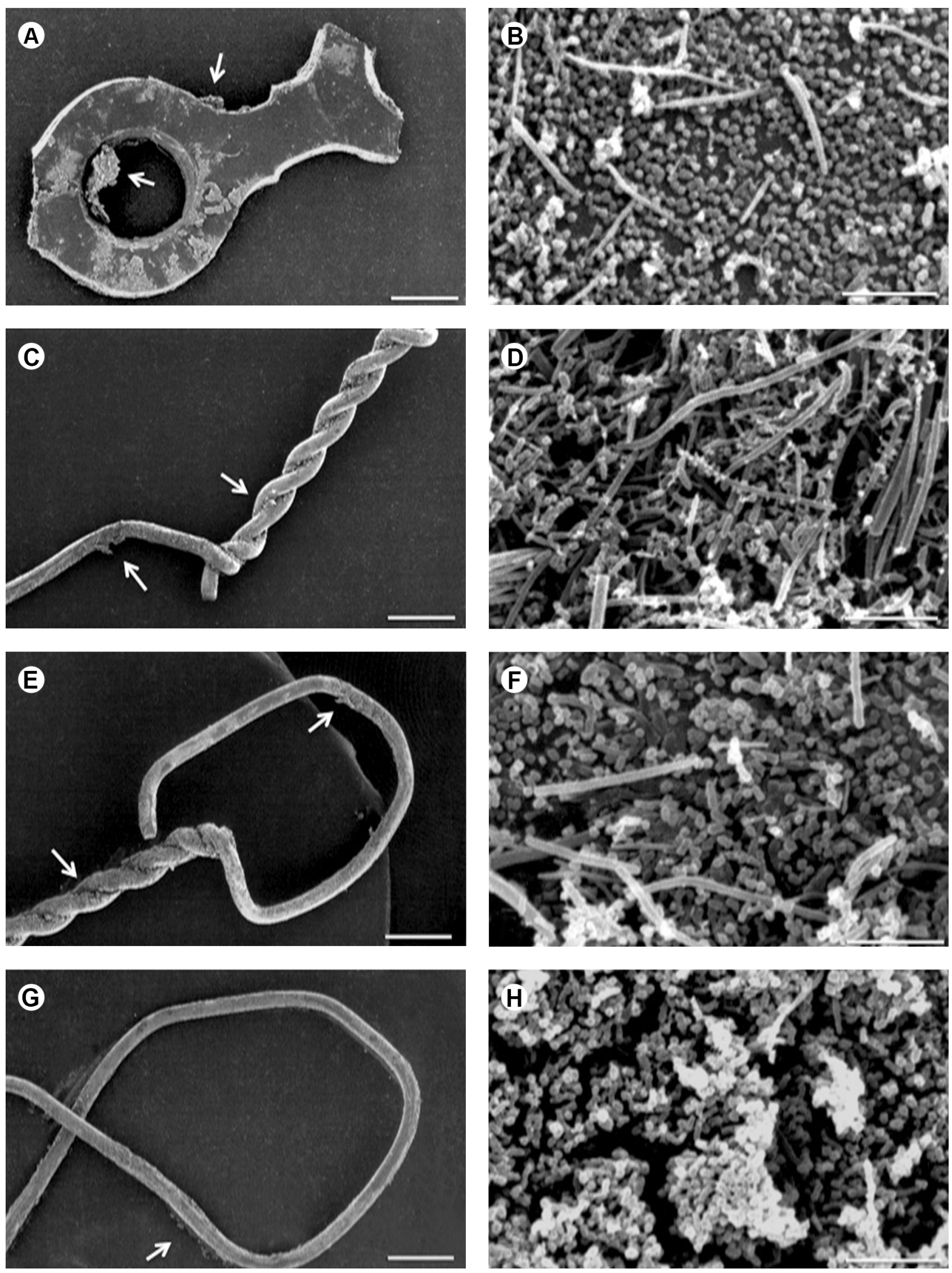

Figure 3: Electron micrographs showing Group I ligatures (elastomeric chain ligature; A-B), Group II (metallic ligature crossing over the archwire; C-D), Group III (metallic ligature crossing under the archwire; E-F), and Group IV (metallic ligature crossing in a figure-eight pattern under the archwire; G-H), showing intense contamination and biofilm formation on the surface of the ligatures (15-5000' magnification). The arrows point to biofilm formation. 
was evaluated by the Shapiro-Wilk test. These transformed variables were analyzed by ANOVA and Tukey-Kramer test for multiple comparisons of means, if significant effect was found. The significance level was fixed at 0.05 .

\section{Results}

Twelve (23\%) ligatures did not exhibit detectable levels of $S$. mutans $(p=0.294)$. These ligatures were equally distributed among the groups.

S. mutans means in Groups I, II, III and IV were, respectively, 62,523 UFC/mg ( $\pm 151,798) ; 27,353$ UFC/ $\mathrm{mg}( \pm 76,181) ; 48,521 \mathrm{UFC} / \mathrm{mg}( \pm 89,872)$ and 37,026 $\mathrm{UFC} / \mathrm{mg}( \pm 82,458)$. Figure 2 demonstrates the $S$. mutans mean distribution among the groups with no statistically significant differences ( $p>0.05$ ).

SEM confirmed the microbial culture results, demonstrating the occurrence of abundant biofilms (Figs. $3 A, C, E, G)$ and abundant microbial contamination for all groups (Fig. 3B,D,F,H).

\section{Discussion}

Fixed orthodontic appliances make oral hygiene difficult, resulting in dental biofilm accumulation. Biofilm retention around (21) and on the surface of orthodontic accessories can lead to enamel demineralization and caries (21). Only a few studies evaluated the effected of ligature wires on biofilm microflora $(13,19,21-23)$. Several authors have investigated how specific materials that tie the archwire to brackets contribute to increased microbial contamination levels, comparing dental biofilm accumulation in areas adjacent to the brackets of elastomeric and metallic ligatures in the buccal dental surface. Nevertheless, in the present study, microbial contamination on the surface of elastomeric chain ligatures and different types of ligature ties was compared.

To the best of the authors' knowledge, this is the first study to evaluate $S$. mutans levels on the surface of the different types of ligature wires. Although the present study did not demonstrate statistical difference between the groups, these results should be interpreted with caution. The authors were able to note that Group I presented higher values than the other groups. It is possible that the employed sample size led to a Type II error, in which there is failure to detect a real difference. It is also possible that there is no difference between the ligatures and this is not a clinical matter for clinicians.

In addition, clinical parameters (data not shown) demonstrated a macroscopic residue accumulation on elastomeric chains. Other studies also reported that residue accumulation is commonly observed in the clinical scenario during orthodontic therapy with different types of devices (24-27). In orthodontic patients, caries prevention represents a significant challenge (27) and requires clinical studies in order to prevent and control caries during orthodontic treatment.

It is also important to emphasize that different methods can be used to investigate $S$. mutans levels. The method used here for the determination of microbial viability by the plate count, is routine in microbiology laboratories worldwide and its accuracy with most organisms is well accepted (28). However, it is possible that the method may have influenced the study results. In 23\% of the ligatures there were no detectable levels of $S$. mutans. Although this is an important limitation of the method, it is important to emphasize that the four analyzed groups were evaluated with the same method.

Briefly, these results highlight the hypothesis that different types of ligature wires may lead to similar dental biofilm accumulations. In health science, replicate findings is always a concern when dealing with systems as complex as the oral environment. Therefore additional studies are necessary to confirm or rebuke the present results in order to aid the implementation of preventive measures to promote oral health during orthodontic treatments.

In conclusion, Streptococcus mutans contamination levels are similar in the different orthodontic ligature types.

\section{Resumo}

Este estudo teve como objetivo testar a hipótese de que os niveis de contaminação de Streptococcus mutans diferem de acordo com o tipo de ligadura ortodôntica. Treze pacientes foram selecionados. Cada quadrante foi submetido aleatoriamente a um dos seguintes protocolos de uso de ligadura: I) ligadura elastomérica, II) ligadura de aço trançada sobre o arco, III) ligadura de aço trançada sob o arco e IV) ligadura de aço em um padrão de "oito" sob o arco. Após sete dias, os dispositivos foram removidos e a contagem das unidades formadoras de colônia de $S$. mutans por mg de peso de biofilme foi determinada. Doze espécimes $(n=3)$ também foram processados para análise por microscopia eletrônica de varredura. Análise de variância e teste de Tukey-Kramer foram utilizados para comparações a fim de avaliar as diferenças de níveis de S. mutans entre os grupos com significância de 5\%. Não houve diferença estatisticamente significante em níveis detectáveis de $S$. mutans entre os grupos ( $p=$ $0,294)$. Os resultados da microscopia eletrônica de varredura mostraram biofilmes abundantes e contaminação microbiana em todos os grupos. Em conclusão, os níveis de contaminação de $S$. mutans são semelhantes nas diferentes ligaduras ortodônticas.

\section{Acknowledgements}

We are indebted to the participants of the study and the financial from The São Paulo State Research Foundation - FAPESP (Grant\# 2013/02536-5).

\section{References}

1. Rosenbloom RG, Tinanoff N. Salivary Streptococcus mutans levels in patients before, during and after orthodontic treatment. Am J Orthod Dentofacial Orthop. 1991;100:35-37.

2. Steinberg D, Eyal S. Initial biofilms formation of Streptococcus sobrinus on various orthodontics appliances. J Oral Rehabil 2004;31:1041-1045.

3. Pramod S, Kailasam V, Padmanabhan S, Chitharanjan AB. Presence of cariogenic streptococci on various bracket materials detected by polymerase chain reaction. Aust Orthod J 2011;27:46-51. 
4. Nelson-Filho $P$, Valdez RM, Andrucioli MC, Saraiva MC, Feres $M$, Sorgi $C A$, et al.. Gram-negative periodontal pathogens and bacterial endotoxin in metallic orthodontic brackets with or without an antimicrobial agent: an in-vivo study. Am J Orthod Dentofacial Orthop 2011;140:e281-e287.

5. Peixoto IT, Enoki C, Ito IY, Matsumoto MA, Nelson-Filho P. Evaluation of home disinfection protocols for acrylic baseplates of removable orthodontic appliances: A randomized clinical investigation. Am J Orthod Dentofacial Orthop 2011;140:51-57.

6. Andrucioli MC, Nelson-Filho P, Matsumoto MA, Saraiva MC, Feres $\mathrm{M}$, de Figueiredo LC, et al.. Molecular detection of in-vivo microbial contamination of metallic orthodontic brackets by checkerboard DNADNA hybridization. Am J Orthod Dentofacial Orthop 2012;141:24-29.

7. Kim SH, Choi DS, Jang I, Cha BK, Jost-Brinkmann PG, Song JS. Microbiologic changes in subgingival plaque before and during the early period of orthodontic treatment. Angle Orthod 2012;82:254-260.

8. Jordan C, Leblanc DJ. Influences of orthodontic appliances on oral populations of mutans streptococci. Oral Microbiol Immunol 2002;17:65-71.

9. Anhoury P, Nathanson D, Hughes CV, Socransky S, Feres M, Chou LL. Microbial profile on metallic and ceramic bracket materials. Angle Orthod 2002;72:338-343.

10. Topaloglu-Ak A, Ertugrul F, Eden E, Ates M, Bulut H. Effect of orthodontic appliances on oral microbiota - 6 month follow-up. J Clin Pediatr Dent 2011;35:433-436.

11. Loesche WJ. Role of Streptococcus mutans in human dental decay. Microbiol Rev. 1986;50:353-380.

12. Marsh PD. Are dental diseases examples of ecological catastrophes? Microbiology. 2003;149:279-294.

13. Brêtas SM, Macari S, Elias AM, Ito IY, Matsumoto MA. Effect of $0.4 \%$ stannous fluoride gel on streptococci mutans in relation to elastomeric rings and steel ligatures in orthodontic patients. Am J Orthod Dentofacial Orthop 2005;127:428-433.

14. Nelson-Filho P, Olmedo LY, Andrucioli MC, Saraiva MC, Matsumoto MA, de Queiroz AM, et al.. Use of the checkerboard DNA-DNA hybridisation technique for in vivo detection of cariogenic microorganisms on metallic brackets, with or without use of an antimicrobial agent. J Dent 2011;39:513-517.

15. Gorelik L, Geiger AM, Gwinett AJ. Incidence of white spot formation after bonding and banding. Am J Orthod 1982;81:93-98.

16. Magno AFF, Enoki C, Ito IY, Matsumoto MAN, Faria G, Filho PN. Invivo evaluation of the contamination of Super Slick elastomeric rings by Streptococcus mutans in orthodontic patients. Am J Orthod
Dentofacial Orthop 2008;133:S104-S109.

17. Türkkahraman $H$, Sayin MO, Bozkurt FY, Yetkin Z, Kaya $S$, Onal S. Archwire ligation techniques, microbial colonization, and periodontal status in orthodontically treated patients. Angle Orthod 2005;75:231236.

18. Gold OG, Jordan HV, VanHoute J. A selective medium for Streptococcus mutans. Arch Oral Biol 1973;18:1357-1364.

19. Takada K, Hirasawa M. A novel selective medium for isolation of Streptococcus mutans. J Microbiol Methods 2005;60:189-193.

20. Aires CP, Del Bel Cury AA, Tenuta LMA, Klein MI, Koo H, Duarte S, et al.. Effect of sucrose and starch on dental biofilm formation and on dentin demineralization. Caries Res 2008;42:380-386.

21. Forsberg CM, Brattström V, Malmberg E, Nord CE. Ligature wires and elastomeric rings: two methods of ligation, and their association with microbial colonization of Streptococcus mutans and lactobacilli. Eur J Orthod 1991;13:416-420.

22. Sukontapatipark W, el-Agroudi MA, Selliseth NJ, Thunold K, Selvig KA. Bacterial colonization associated with fixed orthodontic appliances. A scanning electron microscopy study. Eur J Orthod 2001;23:475-484.

23. Garcez AS, Suzuki SS, Ribeiro MS, Mada EY, Freitas AZ, Suzuki H. Biofilm retention by 3 methods of ligation on orthodontic brackets: a microbiologic and optical coherence tomography analysis. Am J Orthod Dentofacial Orthop. 2011;140:e193-198.

24. Brandão GA, Pereira AC, Brandão AM, de Almeida HA, Motta RR. Does the bracket composition material influence initial biofilm formation? Indian J Dent Res 2015;26:148-151.

25. Levrini L, Novara F, Margherini S, Tenconi C, Raspanti M. Scanning electron microscopy analysis of the growth of dental plaque on the surfaces of removable orthodontic aligners after the use of different cleaning methods. Clin Cosmet Investig Dent 2015;7:125-131.

26. Taha $\mathrm{M}$, El-Fallal $\mathrm{A}$, Degla $\mathrm{H}$. In vitro and in vivo biofilm adhesion to esthetic coated arch wires and its correlation with surface roughness. Angle Orthod 2015;86:285-291.

27. Heymann GC, Grauer D. A contemporary review of white spot lesions in orthodontics. J Esth Rest Dent 2013;25:85-95.

28. Herigstad $B$, Hamilton $M$, Heersink J. How to optimize the drop plate method for enumerating bacteria. J Microbiol Methods 2001;44:121129.

Received June 1, 2016

Accepted March 13, 217 